\title{
Danos em trigo causados pela infecção de Pyricularia grisea
}

\author{
Augusto César Pereira Goulart ${ }^{1}$, Paulo Gervini Sousa ${ }^{1}$, Alfredo Seiti Urashima ${ }^{2}$
}

${ }^{1}$ Embrapa Agropecuária Oeste - Caixa Postal 661 - CEP: 79804-970, Dourados, MS, Brasil, e-mail: goulart@cpao.embrapa.br; ${ }^{2}$ Departamento de Biotecnologia Vegetal, Centro de Ciências Agrárias, Universidade Federal de São Carlos, CEP: 13600-970, Araras, SP.

Autor para correspondência: Augusto César Pereira Goulart

Data da chegada: 02/02/2006. Aceito para publicação em: 10/05/2007.

\section{RESUMO}

Goulart, A.C.P.; Sousa, P.G.; Urashima, A.S. Danos em trigo causados pela infecção de Pyricularia grisea.Summa Phytopathologica, v.33, n.4, p.358-363, 2007.

Este trabalho teve por objetivo quantificar os danos no rendimento de grãos, causados pela infecção natural da brusone (Pyricularia grisea), em diferentes cultivares e linhagens de trigo, na safra agrícola de 2004, no Município de Dourados, Mato Grosso do Sul, isoladamente da ocorrência de outras doenças. Trabalhou-se em condições naturais e sem o emprego de fungicidas, em parcelas experimentais, na Embrapa Agropecuária Oeste e em Indápolis. Após o espigamento, todas as espigas de trigo com sintomas típicos da brusone (ponto preto de infecção na ráquis) foram identificadas e marcadas, em uma área de $1 \mathrm{~m}^{2}$. As espigas doentes e sadias foram colhidas, contadas e trilhadas separadamente. Os danos foram calculados com base na diferença entre o rendimento real e a estimativa do rendimento potencial. Os resultados mostraram que os danos e a incidência da brusone variaram de acordo com as cultivares/linhagens testadas e a região tritícola avaliada. As menores incidências da brusone foram observadas na cv. BR 18-Terena, com $27 \%$ e $42 \%$ de espigas infectadas, nos ensaios instalados na Embrapa Agropecuária Oeste e em Indápolis, respectivamente. $\mathrm{O}$ dano médio devido à brusone, registrado nos 20 materiais testados, foi de $387 \mathrm{~kg} / \mathrm{ha}$, o que representou $10,5 \%$ do rendimento de grãos, no ensaio instalado na Embrapa Agropecuária Oeste. Em Indápolis, os danos foram maiores, atingindo, em média, $609 \mathrm{~kg} / \mathrm{ha}(13,0 \%$ do rendimento de grãos). As perdas em peso por espiga foram maiores $(63,4 \%)$ quando a infecção foi precoce em comparação à infecção tardia $(46,0 \%)$. Verificou-se que houve uma compensação das perdas causadas pela doença, através do melhor desenvolvimento de grãos produzidos abaixo do ponto de estrangulamento da ráquis. Observou-se, também, que em função das espigas brancas sobressaírem-se das demais, pode-se superestimar as perdas.

Palavras-chave adicionais: brusone, perdas, Triticum aestivum, rendimento de grãos

\begin{abstract}
Goulart, A.C.P.; Sousa, P.G.; Urashima, A.S. Damages in wheat caused by infection of Pyricularia grisea. Summa Phytopathologica, v.33, n.4, p.358-363, 2007.

This work was carried out in order to quantify the damages in wheat yield due to natural infection by Pyricularia grisea, (causal agent of wheat blast), in different wheat cultivars and breeding lines, during 2004 crop season, at Dourados county, Mato Grosso do Sul State in the absence of other diseases. The experiments were developed under natural conditions and without fungicide spraying, in experimental plots located at Embrapa Agropecuária Oeste and Indápolis. After heading stage, all spikes that showed the characteristic blast symptoms (black point infection in the rachis), had been identified and marked in an area of the $1 \mathrm{~m}^{2}$. The blast and healthy spikes were harvested, counted and threshed separately. The damages were calculated based on the difference between the actual yield and the estimated yield potential. The results showed that the damages and

the blast incidence had been varied according to cultivars/breeding lines and region. The least incidence of blast were observed on cv. BR 18-Terena, with $27 \%$ and $42 \%$ of infected spikes, from the Embrapa Agropecuária Oeste and Indápolis experiments, respectively. The average damage due to blast, in 20 tested materials, was $387 \mathrm{~kg} / \mathrm{ha}$ or $10.5 \%$ of the yield, in the Embrapa Agropecuária Oeste experiment. In Indápolis, the damages were greater, reaching, in average $609 \mathrm{~kg} /$ ha or $13 \%$ of yield. The head weight loss was greater $(63.4 \%)$ with early infection than with late infection $(46.0 \%)$. It was observed that grains below the infection point in the rachis were larger than the normal ones, thus compensating to some extent the presence of the empty spikelets. Because the white heads were more visible, the yield losses can be overestimated.
\end{abstract}

Additional Keywords: blast, losses, Triticum aestivum, yield

As doenças estão entre os fatores que mais têm contribuído para a limitação de produtividade da triticultura brasileira, sendo favorecidas pelo excesso de chuvas (com períodos longos e freqüentes de molhamento foliar - o que também pode ser proporcionado pela irrigação) e por temperaturas elevadas (12).

A determinação de perdas causadas por um determinado patógeno deveria ser uma das primeiras e mais importantes atividades a ser desenvolvida dentro da Fitopatologia $(12,30)$. Entretanto, a principal dificuldade na determinação de perdas é a disponibilidade de um método que seja adequado e confiável para essa finalidade $(10,30,33)$.

Algum progresso tem sido obtido no que se refere à determinação de perdas causadas por algumas doenças do trigo no Brasil, conforme 
pode ser observado em trabalhos desenvolvidos por Linhares (25), Reis \& Ambrosi (29) e Diehl et al. (4). Reis (28) testou com sucesso uma metodologia que permitiu determinar perdas no rendimento de grãos de trigo causadas por Gibberella zeae. Posteriormente, Reis et al. (30) quantificaram, durante um período de dez anos, na Região Sul do Brasil, danos médios de 5,41\% no rendimento de grãos de trigo causadas por este patógeno. Resultados semelhantes foram obtidos por Casa et al. (3), em Passo Fundo, RS, sendo que o dano médio causado pela $G$. zeae variou de $11,6 \%$ na safra 2002 a $13,4 \%$ na safra 2001. No caso da brusone do trigo, Goulart (7), num período de cinco anos de avaliações, em Mato Grosso do Sul, registrou perdas médias no rendimento de grãos do trigo devido ao ataque de $P$. grisea, da ordem de $32 \%$. Este autor observou ainda, dependendo da época de infecção, perdas em peso por espiga, de até $74 \%$.

A brusone do trigo, causada por Pyricularia grisea (Cooke) Sacc. (sinonímia Pyricularia oryzae Cavara), teleomorfo Magnaporthe grisea $(32,36)$ é a doença da parte aérea da cultura mais recente detectada no Brasil. Foi primeiramente identificada em 1985 no Estado do Paraná (24), sendo a primeira observação no mundo, em condições naturais. Nos anos subsequentes o patógeno disseminou-se para novas áreas, sendo que, atualmente, sua presença já foi registrada nos Estados de São Paulo (22), Mato Grosso do Sul (20), Rio Grande do Sul (26), Goiás (27) e na região dos cerrados do Brasil Central (1), estando assim presente nas principais regiões tritícolas do Brasil.

A severidade da brusone do trigo varia grandemente em função da região, das condições climáticas e da cultivar em questão. A doença vem sendo considerada de importância econômica nos locais onde tem ocorrido, devido à intensidade dos sintomas que produz, principalmente nas espigas. No entanto, as pesquisas que enfocaram danos à produtividade foram todas realizadas na década de 90 (7) quando diferentes cultivares eram empregadas pelos produtores. Dados recentes sobre a importância da doença em cultivares, que estão sendo atualmente semeadas e mesmo linhagens promissoras que vão ser liberadas ao produtor, num futuro próximo, não foram determinados, mostrando uma grande lacuna da pesquisa no Brasil, o único país (além da Bolívia) onde a doença ocorre. Um outro fator que mostra a importância de se conhecer os danos que a doença está causando nas atuais variedades de trigo é que as estratégias recomendadas para o seu controle baseiam-se na época de semeadura (12), no uso de fungicidas aplicados na parte aérea (19) e na diversificação de cultivares, dando preferência àquelas menos suscetíveis, $(2,14,15,37,38)$. Atualmente, a brusone é considerada como uma doença de difícil controle.

Este trabalho teve por objetivo quantificar os danos no rendimento de grãos, causados pela infecção natural da brusone (Pyricularia grisea), em diferentes cultivares e linhagens de trigo, na safra agrícola de 2004, no Município de Dourados, Mato Grosso do Sul, isoladamente da ocorrência de outras doenças.

\section{MATERIAL E MÉTODOS}

O trabalho foi desenvolvido na área experimental da Embrapa Agropecuária Oeste, em Dourados, MS e no Distrito de Indápolis (Município de Dourados, MS), na safra 2004, avaliando-se as seguintes cultivares e linhagens de trigo: GD 94122, MS 98134, BRS 229, IAPAR 78, IPR 87, IPR 110, IPR118, BR11-Guarani, BR 18-Terena, BR 31 Miriti, BR 41 Ofaié, BRS 193, BRS 208, BRS 210, CD 105, IPR 85, Alcover, ES 045, PO 99-O88, PO 00-142, ES 046, PO 99-069 e PO 00-097. Utilizou-se metodologia proposta por Goulart (7), quantificando-se os danos no rendimento de grãos de trigo causadas por P. grisea, isoladamente das demais doenças, em condições naturais e sem o emprego de fungicidas.

A semeadura do trigo no ensaio instalado na Embrapa Agropecuária Oeste foi realizada em 16 de abril e a emergência ocorreu em 22 de abril. No experimento conduzido em Indápolis, a semeadura foi realizada em 08 de abril com a emergência em 17 de abril.

Após o espigamento, quando as plantas apresentavam sintoma típico de brusone nas espigas, caracterizado pelo branqueamento total ou parcial a partir de uma lesão na ráquis, foram delimitadas áreas de $1,0 \mathrm{~m}^{2}$, ao acaso. Em cada área foram marcadas as espigas com sintomas, amarrando-se um fio de lã colorido no pedúnculo das mesmas. Por ocasião da maturação, coletaram-se, separadamente, as espigas sadias e as infectadas, em cada uma das áreas amostradas, dentro de cada parcela, que constaram de 10 fileiras de 5,0 m de comprimento, espaçadas de $0,17 \mathrm{~cm}$. O delineamento experimental utilizado foi o de blocos ao acaso com quatro repetições. As médias foram comparadas pelo teste de Scott-Knott, ao nível de 5\% de probabilidade. Para a análise estatística, os dados de percentagem foram transformados para $\operatorname{arcsen} \sqrt{x / 100}$.

Em laboratório foi contado o número de espigas sadias, infectadas e total. Posteriormente, trilharam-se manualmente as espigas sadias e infectadas de cada amostra, separadamente. Verificou-se que muitas daquelas que não apresentavam sintomas de brusone, no campo, mostravam o sinal típico de infecção na ráquis. Considerou-se como "infecção precoce" aquela verificada no campo e "infecção tardia" aquela determinada por ocasião da trilha em laboratório. Após esse processo, determinou-se o peso de grãos por espigas sadias e infectadas. Os danos foram quantificados, utilizando-se as seguintes fórmulas:

\section{$\mathrm{RP}=(\mathrm{PGES} / \mathrm{NES}) \times \mathrm{NET}$ \\ onde: $\mathrm{RP}=$ rendimento potencial $\left(\mathrm{g} / \mathrm{m}^{2}\right)$ $\mathrm{PGES}=$ peso total de grãos de espigas sadias $/ \mathrm{m}^{2}$ $\mathrm{NES}=$ número total de espigas sadias $/ \mathrm{m}^{2}$ $\mathrm{NET}=$ número total de espigas $/ \mathrm{m}^{2}$ \\ $\mathrm{RR}=\mathrm{PGES}+\mathrm{PGEI}$ \\ onde: $\mathrm{RR}=$ rendimento real $\left(\mathrm{g} / \mathrm{m}^{2}\right)$ $\mathrm{PGEI}=$ peso total de grãos de espigas infectadas $/ \mathrm{m}^{2}$}

\section{$\mathrm{D}=\mathrm{RP}-\mathrm{RR}$}

onde: $\mathrm{D}=\operatorname{danos}\left(\mathrm{g} / \mathrm{m}^{2}\right)$

Entende-se por dano, neste trabalho, a redução na quantidade de produção (rendimento de grãos) causado pela brusone.

\section{RESULTADOS E DISCUSSÃO}

Na Tabela 1 encontram-se os resultados referentes aos danos no rendimento de grãos de trigo em função do ataque da brusone, no ensaio instalado na Embrapa Agropecuária Oeste. Nas diferentes cultivares e linhagens avaliadas, a percentagem de espigas com sintomas de brusone variou de $27 \%$ para a cv. BR 18 -Terena a $95 \%$ para a cv. Alcover e para a linhagem PO 99-088, com uma média de espigas com brusone de $77,8 \%$. Os rendimentos médios real e potencial das cultivares e linhagens de trigo avaliadas foram, respectivamente, $3.190 \mathrm{~kg} / \mathrm{ha}$ e $3.577 \mathrm{~kg} / \mathrm{ha}$. O dano médio na redução do rendimento de grãos dos materiais testados foi de $387 \mathrm{~kg} / \mathrm{ha}$, o que representou $10,5 \%$ de perda. O maior dano percentual foi observado para a cv. BRS 210, com 32,3\% de redução no rendimento de grãos, sendo que a cv. BR 18-Terena foi aquela que apresentou 
Tabela 1. Percentagem de espigas infectadas, rendimento de grãos e perdas causadas por Pyricularia grisea em diferentes cultivares de trigo, safra 2004, no CPAO, em Dourados, MS. Embrapa Agropecuária Oeste, 2004.

\begin{tabular}{|c|c|c|c|c|c|c|}
\hline $\begin{array}{l}\text { Variedade } \\
\text { ou } \\
\text { Linhagen }\end{array}$ & $\begin{array}{c}\text { Ciclo } \\
\text { Vegetativo }\end{array}$ & $\begin{array}{l}\text { Espiga infectada } \\
\text { (\%) de espigas } \\
\text { com sintomas }\end{array}$ & \multicolumn{2}{|c|}{$\begin{array}{l}\text { Rendimento de grãos } \\
\mathrm{kg} / \mathrm{ha}\end{array}$} & \multicolumn{2}{|c|}{ Perdas } \\
\hline ALCOVER & Médio & $95 \mathrm{a}$ & 4190 & 3580 & 610 & 14,6 \\
\hline MS 98134 & Médio & $94 \mathrm{a}$ & 3710 & 3190 & 520 & 14,0 \\
\hline BRS 210 & Médio & $94 \mathrm{a}$ & 3780 & 2560 & 1220 & 32,3 \\
\hline BR 11-GUARANI & Tardio & $91 \mathrm{a}$ & 3390 & 2960 & 430 & 12,7 \\
\hline IPR 87 & Médio & $90 \mathrm{a}$ & 4480 & 3820 & 660 & 14,7 \\
\hline BRS 208 & Médio & $86 \mathrm{~b}$ & 3880 & 3560 & 320 & 8,2 \\
\hline PO 00-142 & Médio & $83 \mathrm{~b}$ & 3350 & 2970 & 380 & 11,3 \\
\hline IAPAR 78 & Tardio & $82 \mathrm{~b}$ & 4180 & 3950 & 230 & 5,5 \\
\hline BRS 229 & Tardio & $80 \mathrm{c}$ & 3540 & 2730 & 810 & 22,9 \\
\hline ES 045 & Precoce/Médio & $64 d$ & 3640 & 3420 & 220 & 6,0 \\
\hline IPR 85 & Precoce & $61 \mathrm{~d}$ & 3070 & 2990 & 80 & 2,6 \\
\hline BR 41-OFAIÉ & Médio & $42 \mathrm{e}$ & 2960 & 2880 & 80 & 2,7 \\
\hline BR 18-TERENA & Precoce/Médio & $27 \mathrm{f}$ & 2850 & 2840 & 10 & 0,4 \\
\hline Média & - & 77,8 & 3577 & 3190 & 387,0 & 10,5 \\
\hline CV $(\%)$ & - & 4,77 & - & - & - & - \\
\hline
\end{tabular}

Tabela 2: Percentagem de espigas infectadas, rendimento de grãos e perdas causadas por Pyricularia grisea em diferentes cultivares de trigo, safra 2004, no Distrito de Indápolis, em Dourados, MS. Embrapa Agropecuária Oeste, 2004.

\begin{tabular}{|c|c|c|c|c|c|c|}
\hline \multirow{2}{*}{$\begin{array}{c}\text { Variedade } \\
\text { ou } \\
\text { Linhagen }\end{array}$} & \multirow{2}{*}{$\begin{array}{c}\text { Ciclo } \\
\text { Vegetativo }\end{array}$} & \multirow{2}{*}{$\begin{array}{l}\text { Espiga infectada } \\
\text { (\%) de espigas } \\
\text { com sintomas }\end{array}$} & \multicolumn{2}{|c|}{$\begin{array}{c}\text { Rendimento de grãos } \\
\mathrm{kg} / \mathrm{ha}\end{array}$} & \multicolumn{2}{|c|}{ Perdas } \\
\hline & & & $\begin{array}{c}\text { Potencial } \\
\text { (estimado) }\end{array}$ & Real & kg/ha & $\%$ \\
\hline ALCOVER & Médio & $98 \mathrm{a}$ & 5050 & 3390 & 1660 & 32,9 \\
\hline IPR 87 & Médio & $98 \mathrm{a}$ & 5280 & 4040 & 1240 & 23,5 \\
\hline ES 046 & Precoce/Médio & $98 \mathrm{a}$ & 4440 & 4080 & 360 & 8,1 \\
\hline IPR 118 & Tardio & 96 a & 3960 & 3010 & 950 & 23,9 \\
\hline BRS 210 & Médio & $96 \mathrm{a}$ & 4700 & 3650 & 1050 & 22,3 \\
\hline MS 98134 & Médio & 96 a & 4450 & 3900 & 550 & 12,3 \\
\hline PO 99-069 & Precoce & $96 \mathrm{a}$ & 4200 & 3950 & 250 & 6,0 \\
\hline BR 31-MIRITI & Médio & $94 \mathrm{a}$ & 4810 & 4290 & 520 & 10,8 \\
\hline IPR 110 & Precoce & $94 \mathrm{a}$ & 3680 & 3320 & 360 & 9,8 \\
\hline BRS 208 & Médio & $94 \mathrm{a}$ & 4510 & 4090 & 420 & 9,3 \\
\hline BR 11-GUARANI & Tardio & $92 \mathrm{~b}$ & 3950 & 3440 & 510 & 12,9 \\
\hline PO 00-097 & Médio & $92 \mathrm{~b}$ & 4190 & 3770 & 420 & 10,0 \\
\hline BRS 193 & Precoce & $90 \mathrm{~b}$ & 4010 & 3270 & 740 & 18,4 \\
\hline CD 105 & Médio & $90 \mathrm{~b}$ & 4820 & 4240 & 580 & 12,0 \\
\hline BR 41-OFAIÉ & Médio & $89 \mathrm{~b}$ & 3520 & 3150 & 370 & 10,5 \\
\hline BRS 229 & Tardio & $82 \mathrm{c}$ & 3850 & 3230 & 620 & 16,1 \\
\hline GD 94122 & Médio & $82 \mathrm{c}$ & 4450 & 4100 & 350 & 7,8 \\
\hline IPR 85 & Precoce & $80 \mathrm{c}$ & 5170 & 4510 & 660 & 12,8 \\
\hline IAPAR 78 & Tardio & $70 \mathrm{~d}$ & 4990 & 4610 & 380 & 7,6 \\
\hline BR 18-TERENA & Precoce/Médio & $42 \mathrm{e}$ & 4390 & 4200 & 190 & 4,3 \\
\hline Média & - & 88,4 & 4421 & 3812 & 609 & 13,0 \\
\hline CV $(\%)$ & - & 4,25 & - & - & - & - \\
\hline
\end{tabular}


Tabela 3. Peso de grãos e número de espigas com brusone, número e peso de espigas sadias, peso de grãos por espiga e danos em relação às espigas sadias, em trigo, cv. BR 18-Terena, em Dourados, MS, no ano de 2004. Embrapa Agropecuária Oeste, Dourados, MS. 2005.

\begin{tabular}{|c|c|c|c|c|c|c|c|c|c|c|c|}
\hline \multirow[t]{2}{*}{ Repetições } & \multicolumn{2}{|c|}{$\begin{array}{c}\text { Peso de grãos de } \\
\text { espiga com brusone } \\
\left(\mathrm{g} / \mathrm{m}^{2}\right)\end{array}$} & \multicolumn{2}{|c|}{$\begin{array}{l}\text { Número de espigas } \\
\text { com brusone }\end{array}$} & \multicolumn{2}{|c|}{ Espiga sadia } & \multicolumn{3}{|c|}{ Peso de grãos/espiga (g) } & \multicolumn{2}{|c|}{$\begin{array}{c}\text { Dano em relação à } \\
\text { espiga sadia (\%) }\end{array}$} \\
\hline & $\begin{array}{c}\text { Infecção } \\
\text { precoce }\end{array}$ & $\begin{array}{c}\text { Infecção } \\
\text { tardia }\end{array}$ & $\begin{array}{l}\text { Infecção } \\
\text { precoce }\end{array}$ & $\begin{array}{c}\text { Infecção } \\
\text { tardia }\end{array}$ & Número & $\begin{array}{l}\text { Peso } \\
\left(\mathrm{g} / \mathrm{m}^{2}\right)\end{array}$ & Sadia & $\begin{array}{c}\text { Infecção } \\
\text { precoce }\end{array}$ & $\begin{array}{c}\text { Infecção } \\
\text { tardia }\end{array}$ & $\begin{array}{l}\text { Infecção } \\
\text { precoce }\end{array}$ & $\begin{array}{c}\text { Infecção } \\
\text { tardia }\end{array}$ \\
\hline 1 & 18,2 & 30,6 & 52 & 84 & 340 & 212 & 0,62 & 0,35 & 0,36 & 43,5 & 41,9 \\
\hline 2 & 16,5 & 30,8 & 71 & 70 & 337 & 228 & 0,67 & 0,23 & 0,44 & 65,7 & 34,3 \\
\hline 3 & 16,4 & 30,6 & 97 & 85 & 340 & 236 & 0,69 & 0,17 & 0,36 & 75,3 & 47,8 \\
\hline 4 & 16,3 & 29,8 & 63 & 75 & 335 & 240 & 0,72 & 0,26 & 0,40 & 63,9 & 44,4 \\
\hline 5 & 17,3 & 25,1 & 67 & 81 & 338 & 242 & 0,72 & 0,26 & 0,31 & 63,9 & 56,9 \\
\hline 6 & 16,2 & 29,2 & 71 & 80 & 342 & 251 & 0,73 & 0,23 & 0,36 & 68,4 & 50,7 \\
\hline Média & 16,8 & 29,4 & 70,2 & 79,2 & 338,7 & 234,8 & 0,69 & 0,25 & 0,37 & 63,4 & 46,0 \\
\hline
\end{tabular}

Tabela 4: Dados climáticos registrados no período de 16 de junho a 16 de julho dos anos de 2003 e 2004. Embrapa Agropecuária Oeste, Dourados, MS. 2005

\begin{tabular}{cccccc}
\hline Safra & Precipitação $(\mathbf{m m})$ & Temperatura média $\left({ }^{\circ} \mathbf{C}\right)$ & Umidade relativa $(\%)$ & U.R. $>\mathbf{9 0 \%}\left(\mathbf{n}^{\mathbf{0}}\right.$ dias) & Período crítico \\
\hline 2003 & 48,7 & 22,5 & 80,1 & 7 & 10 \\
2004 & 6,9 & 18,2 & 77,4 & 5 & 3 \\
\hline
\end{tabular}

U.R. $=$ Umidade relativa

Período crítico $=10-14$ horas de molhamento das espigas

Fonte: Estação Meteorológica da Embrapa Agropecuária Oeste

o menor dano, com apenas $0,4 \%$ de redução da produtividade.

No caso do ensaio instalado no distrito de Indápolis (Tabela 2), em função de uma maior severidade da doença, foram detectadas maiores percentagens de espigas com brusone e, consequentemente, maiores reduções no rendimento de grãos, em comparação aos resultados obtidos no ensaio instalado na Embrapa Agropecuária Oeste. Assim, a percentagem de espigas com brusone variou de $42 \%$ para a cv. BR 18-Terena a 98\% para os materiais IPR 87, Alcover e ES 046. A média de espigas com brusone foi de $88,4 \%$. Os rendimentos médios real e potencial das cultivares e linhagens de trigo avaliadas foram, respectivamente, $3.812 \mathrm{~kg} / \mathrm{ha}$ e $4.421 \mathrm{~kg} / \mathrm{ha}$. O dano médio na redução do rendimento de grãos dos materiais testados foi de $609 \mathrm{~kg} /$ ha, o que representou $13,0 \%$. O maior dano percentual foi observado para a cv. Alcover, com 32,9\% de redução no rendimento de grãos, sendo que a cv. BR 18-Terena foi aquela que apresentou o menor dano, com apenas $4,3 \%$ de redução da produtividade.

As perdas em relação às espigas sadias devido ao ataque da brusone do trigo encontram-se na Tabela 3. A cultivar utilizada para esta avaliação foi a BR 18-Terena. Considerando-se a época de infecção das espigas, verificou-se que, quando a infecção ocorreu mais cedo, as perdas foram maiores. Os resultados mostraram danos médios de $63,4 \%$ quando a infecção foi precoce e de $46,0 \%$ quando a infecção foi tardia em comparação às espigas sadias.

Os danos no rendimento provocados pela incidência de doenças nas plantas variam, entre outros fatores, conforme a cultura, o patógeno, a localidade, as condições ambientais, a suscetibilidade da cultivar, a severidade da doença e as medidas de controle empregadas $(8,31)$. Considerando-se estes aspectos, é difícil dizer quanto uma planta poderia tolerar uma doença, sem sofrer perdas significativas na produtividade, sendo que a intensidade da perda na produção é determinada, geralmente, pela época em que ocorre a infecção e pelo órgão afetado na planta $(9,11)$. No caso específico deste trabalho, verificou-se que o dano foi dependente da cultivar/ linhagem testada, bem como do local onde os experimentos foram instalados. Segundo Casa et al. (3) isto pode ocorrer em virtude de diferentes condições favoráveis ou não à infecção, o que determina uma maior ou menor severidade da doença.

A severidade da brusone do trigo varia grandemente em função das condições climáticas sendo que temperaturas de $21-27^{\circ} \mathrm{C}$ e $10-14$ horas de molhamento das espigas favorecem a ocorrência desta doença (7). Na Tabela 4, encontram-se os dados climáticos, no período de espigamento do trigo, na região de Dourados, onde os ensaios foram conduzidos. Observa-se que na safra de 2004, as condições de temperatura e umidade foram altamente favoráveis à ocorrência da brusone, ocorrendo dez períodos críticos (período de tempo identificável durante o qual o período de molhamento e a temperatura são favoráveis à esporulação, liberação, disseminação e infecção), justificando a elevada percentagem de espigas com brusone e os danos no rendimento observados neste trabalho bem como em lavouras comerciais em Mato Grosso do Sul (5). Para se ter uma idéia da importância das condições climáticas na ocorrência de uma epidemia de brusone, observa-se na Tabela 4, safra 2003, que as condições de clima prevalentes no período não foram as ideais para a brusone, explicando a baixa incidência da doença nas lavouras de trigo na região, sem prejuízo no rendimento da cultura.

Observou-se neste trabalho, para as diferentes cultivares e linhagens testadas, que nem sempre as maiores perdas foram detectadas naquelas cultivares ou linhagens que apresentaram as maiores percentagens de espigas com brusone (Tabelas 1 e 2). Isto pode ser explicado, uma vez que os maiores ou menores danos ocasionados pela brusone estão diretamente relacionados à época de infecção da espiga pelo fungo e não em função da incidência da brusone na espiga, sendo maiores quando a infeção ocorre na época de formação dos grãos (infecção precoce), o que pode ser observado na Tabela 3 e em resultados obtidos anteriormente por Goulart (7). No caso do ensaio instalado em Indápolis, não se obteve relação entre a percentagem de espigas com brusone com o dano $\left(\mathrm{r}^{2}=0,15 ; \mathrm{p}>0,5\right)$. Já no ensaio instalado em Dourados, obteve-se esta relação $\left(r^{2}=0,44 ; p<0,01\right)$, significando que apenas $44 \%$ da variação no dano pode ser explicada pela percentagem de espigas com brusone.

Com relação á incidência da brusone nas espigas de trigo, houve diferença de comportamento entre os materiais testados, demonstrando 
que, até o momento, não se dispõe de cultivares/linhagens imunes à esta doença, o que vem corroborar resultados obtidos anteriormente por Igarashi \& Utiamada (23), Igarashi (21), Goulart \& Paiva $(14,15)$, Arruda et al. (2), Urashima et al. (35) e Urashima et al. (38). Este comportamento dos materiais testados evidencia reação diferencial das cultivares/linhagens à $P$. grisea, o que pode ser atribuído a alta variabilidade de isolados que compõem a população do patógeno (35). De todos os materiais testados, a cultivar BR 18-Terena foi a que apresentou a menor incidência de espigas com brusone, nos dois locais de condução dos ensaios, (Tabelas 1 e 2), porém, apresentando reação de suscetibilidade, de acordo com os parâmetros de resistência definidos por Arruda et al. (2). Observações ao nível de lavoura (5) e de ensaios realizados no campo em Mato Grosso do $\operatorname{Sul}(14,15,18,34)$ demonstraram o bom comportamento da cultivar BR 18-Terena frente ao fungo $P$. grisea, confirmando os resultados obtidos neste trabalho. Por outro lado, resultados obtidos por Arruda et al. (2), provenientes de trabalhos realizados em casa de vegetação, com inoculação do fungo nas plantas de trigo, utilizando isolados do Paraná, demonstraram reação de resistência da cultivar BR 18-Terena na fase vegetativa e de suscetibilidade na fase reprodutiva. Assim como discutido anteriormente, esta diferença nos resultados entre estes estudos pode ser atribuída a alta variabilidade de isolados que compõem a população do patógeno (35). Conforme observado neste estudo e naquele desenvolvido por Arruda et al. (2), a maioria das cultivares/linhagens mostrou reação de alta suscetibilidade das espigas à brusone, reforçando observações anteriores a respeito da importância que esta doença assume dentro do contexto da triticultura brasileira em função da falta de resistência da cultivares atualmente cultivadas por ocasião da formação dos grãos $(15,18,35)$. Outro aspecto que pode influenciar na maior ou menor percentagem de espigas com brusone é o ciclo vegetativo da cultivar. De maneira geral, as cultivares de ciclo vegetativo mais longo (tardio) têm tendência de apresentar uma menor incidência de espigas com brusone, o que pode ser explicado devido a um possível escape, uma vez que o período de espigamento das mesmas ocorre quando as condições de umidade e temperatura do ar não são favoráveis ao patógeno, o que não ocorreu neste trabalho, conforme pode ser observado nas Tabelas 1 e 2.

A importância econômica da brusone do trigo decorre das reduções que provoca no rendimento e na qualidade de grãos, que, quando infectados, apresentam-se enrugados, pequenos, deformados e com baixo peso específico, conforme observado nesse trabalho. Em conseqüência, a maioria desses grãos é eliminada no processo de colheita e beneficiamento. Isso explica a baixa incidência de $P$. grisea no trigo comercial ou em sementes fiscalizadas, conforme demonstrado por Goulart et al. $(16,17)$.

Notou-se também nesse ensaio que em grande número de espigas infectadas ocorria, abaixo do ponto de estrangulamento da ráquis, uma produção de grãos de tamanho bem maior que o normal, fruto de maior acúmulo de nutrientes nesse local. Dessa forma, a translocação de seiva ficou restrita a essa região da espiga, uma vez que a ação do fungo na ráquis impediu a passagem da mesma para a parte superior da espiga prejudicando o desenvolvimento de grãos nessas regiões. Isso sugere uma compensação de produção por parte da planta. Observou-se, ainda, que as espigas infectadas por P. grisea, apresentando-se brancas, sobressaiam-se das demais (verdes e sadias), o que determinava uma ilusão visual de estimativas de níveis de infecção e de perdas superiores às reais.

A intensidade da perda na produção é determinada, geralmente, pela época em que ocorre a infecção e pelo órgão afetado na planta. No caso da brusone do trigo, conforme observado nesse trabalho e segundo
Goulart (6), as maiores perdas ocorrem quando a infecção tem início nas fases de florescimento e formação de grãos, o que pode ser considerado como sendo a "infecção precoce" determinada nesse trabalho. No caso desta doença, a situação ainda é mais séria uma vez que o principal órgão afetado pela doença é a espiga.

Em função dos danos que esta doença provoca, torna-se fundamental que o seu controle seja feito de maneira eficiente, o qual depende da conjugação de medidas que devem ser adotadas adequadamente e no momento oportuno. Dentre essas, o controle preferencial da doença pode ser obtido pela utilização de cultivares com maior nível de resistência (como a BR 18Terena, por exemplo) e pela semeadura em época adequada para a região de cultivo (em Mato Grosso do Sul sugere-se a semeadura após o primeiro decêndio de abril, com o objetivo de evitar condições favoráveis à ocorrência da doença por ocasião do espigamento do trigo). Uma vez que a grande maioria das variedades são suscetíveis à brusone, a aplicação de fungicidas poderá constituir-se em mais uma ferramenta no controle integrado da doença, desde que realizada com base na análise de custo/benefício, mesmo sabendo da baixa eficiência de controle dessa doença, que é de apenas $30 \%$ a $50 \%$, no máximo $(13,19)$.

\section{REFERÊNCIAS BIBLIOGRÁFICAS}

1. Anjos, J.R.N. dos; Silva, D.B. da; Charchar, M.J.D.; Rodrigues, G.C. Ocorrência de brusone (Pyricularia grisea) em trigo e centeio na região dos cerrados do Brasil Central. Pesquisa Agropecuária Brasileira, Brasília, DF, v.31, n.1, p.79-82, jan. 1996.

2. Arruda, M.A., Bueno, C.R.N.C.; Zamprogno, K.C.; Lavorenti, N.A.; Urashima, A.S. Reação de trigo a Magnaporthe grisea nos diferentes estádios de desenvolvimento. Fitopatologia Brasileira, Brasília, DF, v.30, n.2, p.121-126, 2005.

3. Casa, R.T.; Reis, E.M.; Blum, M.M.C.; Bogo, A.; Scheer, O.; Zanata, T. Danos causados pela infecção de Gibberella zeae em trigo. Fitopatologia Brasileira, Brasília, DF, v.29, n.3, p.289$293,2004$.

4. Diehl, J.A.; Tinline, R.D.; Kochhann, R.A. Perdas em trigo causadas pela podridão comum de raízes no Rio Grande do Sul, 197981. Fitopatologia Brasileira, Brasília, DF, v.8, n.3, p.507-511, 1983.

5. Goulart, A.C.P. Brusone do trigo diminui rendimento dos grãos. A Lavoura, Rio de Janeiro, ano 107, n.650, p.18-21, set. 2004a.

6. Goulart, A.C.P. Doenças do trigo e reflexos na produtividade. Correio Agrícola, São Paulo, n.1, p.8-13, 1994.

7. Goulart, A.C.P. Perdas em trigo causadas pela brusone. In: Workshop de Epidemiologia de Doenças de Plantas, 1., 2005, Viçosa, MG. Quantificação de perdas no manejo de doenças de plantas: anais. Viçosa, MG: Universidade Federal de Viçosa, 2004b. p. $123-130$.

8. Goulart, A.C.P. Trigo: Segurança dobrada. Caderno Téenico Cultivar Trigo. Pelotas, p.8-10, abr. 2005d. Circula encartado em Cultivar: Grandes Culturas, n.72, abr.2005.

9. Goulart, A.C.P. Trigo: chave do problema. Caderno Técnico Cultivar Trigo, Pelotas, p.7-10. maio 2005a. Circula encartado em Cultivar: Grandes Culturas Pelotas, n.73, maio 2005.

10. Goulart, A.C.P. Trigo: conhecendo os inimigos. Caderno Técnico Cultivar Trigo, Pelotas, p.4-6. maio 2005b. Circula encartado em Cultivar: Grandes Culturas Pelotas, n.73, maio 2005.

11. Goulart, A.C.P. Trigo: escolhendo os fungicidas. Caderno Técnico Cultivar Trigo, Pelotas, p.11-12. maio 2005c. Circula encartado em Cultivar: Grandes Culturas Pelotas, n.73, maio 2005.

12. Goulart, A.C.P.; Nasser, L.C.B.; Azevedo, J.A. de. Manejo integrado de doenças em trigo irrigado sob pivô central na região do cerrado. In: Zambolim, L. (Ed.). Manejo integrado: fitossanidade: cultivo protegido, pivô central e plantio direto. Viçosa, MG:Universidade Federal de Viçosa, 2001. p.137-163. 
13. Goulart, A.C.P.; Paiva, F. de A. Avaliação de fungicidas no controle da brusone "Pyricularia oryzae" do trigo (Triticum aestivum). Fitopatologia Brasileira, Brasília, DF, v.18, n.2, p.167-173, 1993.

14. Goulart, A.C.P.; Paiva, F. de A. Incidência da brusone (Pyricularia oryzae) em diferentes cultivares de trigo (Triticum aestivum) em condições de campo. Fitopatologia Brasileira, Brasília, DF, v. 17, n.3, p.321-325, set. 1992 .

15. Goulart, A. C. P.; Paiva, F. de A. Response of wheat cultivar and breeding lines to blast (Pyricularia grisea) under field conditions, 1991. Annual Wheat Newsletter, Fort Collins, v.39, p.109. 112, June 1993.

16. Goulart, A.C.P.; Paiva, F. De A.; Andrade, P.J.M. Fungi incidence in wheat seeds produced in Mato Grosso do Sul State. Annual Wheat Newsletter, Fort Collins, v.40, p.75-76, 1994.

17. Goulart, A.C.P.; Paiva, F. De A.; Andrade, P.J.M. Qualidade sanitária de sementes de trigo produzidas no Mato Grosso do Sul, safras 1987 a 1992. Summa Phytopathologica, Jaguariúna, v.21, n.3/4, p.235-238, 1995.

18. Goulart, A.C.P.; Paiva, F. De A.; Andrade, P.J.M. Relação entre a incidência da brusone do trigo a presença de Pyricularia grisea nas sementes colhidas. Fitopatologia Brasileira, Brasília, DF, v.20, n.2, p.184-189, 1995.

19. Goulart, A.C.P.; Paiva, F. De A.; Melo Filho, G.A. De; Richetti, A. Efeito da época e do número de aplicações dos fungicidas tebuconazole e mancozeb no controle da brusone (Pyricularia grisea) do trigo; viabilidade técnica e econômica. Fitopatologia Brasileira, Brasília, DF, v.21, n.3, p.381-387, 1996.

20. Goulart, A.C.P.; Paiva, F. De A.; Mesquita, A.N. de. Ocorrência da brusone (Pyricularia oryzae) do trigo (Triticum aestivum) em Mato Grosso do Sul. Fitopatologia Brasileira, Brasília, DF, v.15, n.1, p.112-114, mar. 1990.

21. Igarashi, S. Uma análise da ocorrência de "brusone" do trigo no Paraná. [S.1.: s.n., 1988]. 19p. Trabalho apresentado no Seminário sobre Melhoramento para Resistência a Enfermidades, Passo Fundo, RS, ago. 1988.

22. Igarashi, S. Update on wheat blast (Pyricularia oryzae) in Brazil. In: Saunders, D.A. (Ed.). Wheat for nontraditional warm areas: a proceedings of the International Conference, Foz do Iguaçu, Brazil, 1990. México, DF: CIMMYT, 1991. p.480-483.

23. Igarashi, S.; Utiamada, C.M. Pyricularia sp. em trigo II. Resistência varietal. In: Reunião Nacional de Pesquisa de Trigo, 14., 1986, Londrina. Resumos... Londrina: IAPAR, [1986]. p. 59.

24. Igarashi, S.; Utiamada, C.M.; Igarashi, L.C.; Kazuma, A.H.; Lopes, R.S. Pyricularia sp. em trigo. Ocorrência de Pyricularia sp. no Estado do Paraná. Fitopatologia Brasileira, Brasília, DF, v.11, n.2, p.351, jun.1986. (Resumo 150)

25. Linhares, W.I. Perdas de produtividade ocasionadas por oídio na cultura de trigo. Fitopatologia Brasileira, Brasília, DF, v. 13 n.1, p.74-75, abr. 1988.

26. Picinini, E.C.; Fernandes, J.M.C. Ocorrência da brusone (Pyricularia oryzae) em lavouras comerciais de trigo (Triticum aestivum) no Estado do Rio Grande do Sul. Fitopatologia Brasileira, Brasília, DF, v.15, n.1, p.83-84, mar. 1990.

27. Prabhu, A.S.; Filippi, M.C.; Castro, N. Pathogenic variation among isolate of Pyricularia oryzae infecting rice, wheat and grasses in Brazil. Tropical Pest Management, London, v.38, n.4, p.367371, 1992.

28. Reis, E.M. Metodologia para determinação de perdas causadas em trigo por Gibberella zeae. Fitopatologia Brasileira, Brasília, DF, v.11, n.4, p.951-955, dez. 1986.

29. Reis, E.M.; Ambrosi, I. Economical threshold to control leaf blights of triticale by spraying fungicides. In: International Triticale Symposium, 2., 1990, Passo Fundo. Abstracts... Passo Fundo: EMBRAPA: CIMMYT: ITA, 1990. p.30.

30. Reis, E.M.; Blum, M.M.C.; Casa, R.T.; Medeiros, C.A. Grain losses caused by the infection of wheat heads by Gibberella zeae in southern Brazil, from 1984 to 1994. Summa Phytopathologica, Jaboticabal, v.22, p.123-137, abr./jun. 1996.

31. Reis, E.M.; Casa, R.T.; Medeiros, C.A. Diagnose, patometria e controle de doencas de cereais de inverno. Londrina: ES Comunicação, 2001. 94p.

32. Rossman, A.Y.; Howard, R.J.; Valente, B. Pyricularia grisea, the correct name for the rice blast disease fungus. Mycologia, New York, v.82,n.4, p.509-512, 1990.

33. Sah, D.N.; Mackenzie, D.R. Methods of generation different levels of disease epidemics in loss experiments. In: TENG, P.S. (Ed.). Crop loss assessment and pest management. St. Paul: APS, 1987. p.90-95.

34. Sartori, J.F.; Gomes, E.P. Avaliação preliminar da reação de cultivares de trigo à brusone em condições de campo. Comunicado Técnico EMBRAPA/CNPT, n.1, 1988. 3p.

35. Urashima, A.S.; Hashimoto, Y., Don, L.D., Kusaba, M., Tosa, Y. Nakayashiki, H.; Amyama, S. Molecular analysis of the wheat blast population in brazil with a homolog of retrotransposon MGR583. Annals of the Phytopathological Society of Japan, Tokyo, v.65, p. 429-436, 1999.

36. Urashima, A.S.; Igarashi, S.; Kato, H. Host range, mating type, and fertility of Pyricularia grisea from wheat in Brazil. Plant Disease, St. Paul, v.77, n.12, p.1211-1216, Dec. 1993.

37. Urashima, A.S.; Kato, H. Varietal resistance and chemical control of wheat blast fungus. Summa Phytopathologica, Jaguariúna, v.20, n.2, p.107-112, abr./jun. 1994

38. Urashima, A.S.; Lavorent, N.A.; Goulart, A.C.P.; Mehta, Y.R. Resistance spectra of wheat cultivars and virulence diversity of Magnaporthe grisea isolates in Brazil. Fitopatologia Brasileira, Brasília, DF, v.29, n.5, p.511-518, 2004 